sented in a chapter called "The quest for omega", and they are credited to very recent laboratory results. Where are the cold dark matter candidates like Weakly Interacting Massive Particles and axions; where the baryonic candidates (MACHOs and brown dwarfs), strings, and all the rest? Where, for that matter, is the 20-year history of neutrinos as dark matter? Nowhere. And, indeed, omega is nowhere defined.

The intended audience consists of the customary intelligent laymen and women (the book is generally careful about such matters), with zero knowledge but infinite capacity. These probably mythical persons will not notice and may not care about numerical and historical errors and omissions. But incomprehensible explanations are surely fatal. Said readers will be left feeling either unintelligent or mistreated. Thus, I suspect they will cast the book aside about the time (circa $300 \mathrm{BC}$ or the middle of Chapter 1) when Aristarchus of Samos is trying to learn the distances to the Moon and Sun.

Aristarchus' attempt to get the solar distance from the unequal lengths of the four main phases of the Moon (from new to first quarter, first quarter to full, and so on) is extraordinarily clever. Why did he fail? The Moon's orbit is an ellipse, not a circle, but Ferguson never tells you this. The figures do not seem to help difficult geometric concepts; author and illustrator conspire togeth-

er to keep the reader from discovering that, if you can measure two angles of a triangle and the included side, you have the rest.

Modern territory brings us to ways of measuring distances to galaxies, clusters and quasars very far from our own Milky Way. Those involving sources of known absolute brightness come across fairly well, but the more complex ones could not be understood from what is given even by infinite intelligence. You always need to measure two things (and often do some modelling as well). For distances to gravitationally lensed quasars, the two things are the time delay between flares seen in separate images and their angular separation on the sky. Only the time delay is mentioned. For the hot gas in rich clusters of galaxies, the two are the degree to which gas scatters photons of the cosmic microwave background (for which the author gets the sign wrong) and its X-ray emission. Only the scattering is mentioned.

Many popular books of popular science, both in and out of my field of astronomy, have passed the test: "Would you be reading this if you hadn't been asked to review it?", including ones by Fred Hoyle, Carl Sagan, Isaac Asimov, Peter Medawar, Malcolm Longair, Martin Rees, Walter Sullivan and Stephen Jay Gould. Measuring the Universe is not one of these books.

Virginia Trimble is in the Department of Physics, University of California, Irvine, California 92697-

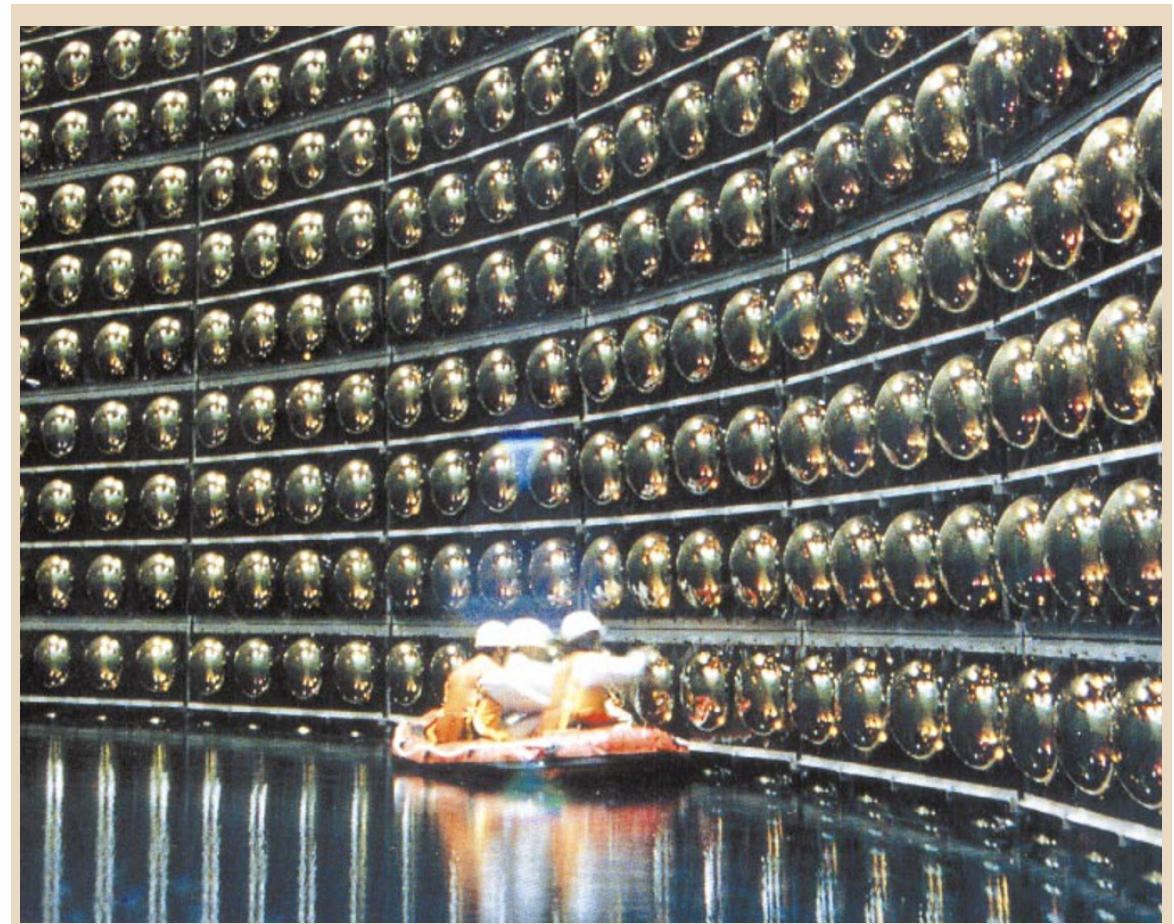

\title{
Underground enlightenment
}

Technicians travel by raft under the giant dome of the Kamiokande neutrino detector, a kilometre under a mountain near Tokyo, to clean the faces of photomultipliers. These detect the presence of neutrinos by the light created when they collide with atoms. This is just one of 220 mind-expanding illustrations - with clear, informative text about the advances physics has made this century-in Physics in the Twentieth Century by Curt Suplee (Abrams, \$49.50, £32).
4575, and in the Astronomy Department, University of Maryland, College Park, Maryland 20742, USA.

\section{Further astronomy}

Astronomy in Prehistoric Britain and Ireland by Clive Ruggles

Yale University Press, \$65, £45

\section{Sustaining hopes for change}

\section{The Brundtland Commission's Report - 10 Years}

edited by Guri Bang Søfting, George Benneh, Kjetil Hindar, Lars Walløe and Anders Wijkman

Scandinavian University Press/Research Council of Norway: 1998. 234 pp. NKr298

\section{Peter Doran}

More than ten years after the landmark publication of Our Common Future by the World Commission on Environment and Development (WCED), the questions that face the growing community of policy-makers and researchers in sustainable development have changed radically.

Research agendas are no longer driven simply by a need to understand the various categories and causes of unsustainability in our social, economic and environmental decision-making. They are increasingly concerned with knowledge itself and reflect the important challenge of making better use of existing information and framing that knowledge in a way that makes it useful and accessible at all levels of decision-making.

At the local level, for example, research that leads to understanding and action must often be pursued with the participation of local people. Such approaches to knowledgegathering most frequently occur where empowerment, motivation, understanding and democracy have become interlinked. The Nordic countries' enthusiastic response to the sustainable-development movement seems to support the view that a democratic culture and an informed citizenry provide the most fertile soil for new values and behaviour patterns to take hold.

These changes to the research agenda for sustainable development are reflected in the broad recommendations in The Brundtland Commission's Report. This is a collection of papers produced for an international research conference in Oslo to mark the tenth anniversary of the publication of the WCED report. The conference was designed to take stock of the "evolution of sustainable development up to the present", and the Norwegian Research Council is already planning a research programme around some of the points that came out of it.

Blessed with an optimism that can 
accompany a world view formed by the Scandinavian experience, the editors attribute the popularization of the term "sustainable development" to the work of the WCED, and suggest that it is "leading to a historic shift in all of our societies". Scandinavian countries have certainly taken a lead in championing special issues raised in the aftermath of the 1992 United Nations Conference on Education and Development. Finland, for example, has undertaken an excellent research programme to investigate the implications of sustainable development on a social dimension. Norway has taken a special interest in the issues of production and consumption.

In her contribution to the volume, Gro Harlem Brundtland, who chaired the commission named after her, explains how a transformation in the political climate in Western countries has helped to extend this change in the fortunes of the sustainabledevelopment agenda beyond Scandinavia. The WCED reported during a period of political conservatism and economic liberalism in Western countries, and few governments supported the calls for stronger governance in their economies. The recent ascendancy of social democratic-led coalitions, in some cases including Green Party representatives, marks a dramatic shift in Europe's political and democratic landscape, and transforms the prospects for policies of sustainable development.

These prospects are also investigated in the context of the developing countries. Madhav Gadgil observes that, while the globalization of the flow of goods and services has not reached poorer countries, better access to information can make it easier for ordinary people to be involved in planning and managing change, contributing to a shift from control-and-command structures to a culture of inform-and-share.

Gadgil cites the example of the Kerala Sastra Sahitya Parishat (KSSP), a popularscience movement in India which focuses on health and environment issues and invites ordinary people to question accepted patterns of development.

The importance of institutionalizing new approaches to knowledge and learning by society is a recurring theme of this volume, which is a galaxy of potential thesis topics and book projects.

In a section on production and consumption, John R. Ehrenfeld highlights the importance of indicators as a means of maximizing the chance that societies will be able to make the necessary changes. Such indicators, together with institutionalized learning, he argues, are essential if sustainable patterns of production and consumption are to be achieved.

Peter Doran is in the Department of Humanities, Magee University College, Northland Road, Derry BT49 7JL, Northern Ireland, UK.

\section{Science in culture}

\section{Sexy stamens and provocative pistils}

The taxonomic science of the flower bed Martin Kemp

$\boldsymbol{F}^{\circ}$ or centuries the study of flowers and the cultivation of gardens were deemed to be safe pursuits for young ladies. The behaviour of animals, by contrast, was all too likely to provoke difficult questions about sexual activity. Carl Linnaeus's sexual system for the classification of plants, based on stamens and pistils, changed all that.

Introduced to a worldwide readership in his Philosophia Botanica of 1751, Linnaeus's principles attracted fervent adherents and keen opposition. Among the devotees was Erasmus Darwin, Charles's grandfather, who was an enthusiast of the French Revolution and adopted a radically libertarian stance on social matters. Erasmus's scientific poem, "The loves of plants", published in 1789 as part II of The Botanic Garden, blends sober scientific analysis with poetic rapture, the latter typified by his evocation of the polygamy practised by Gloriosa superba:

Proud Gloriosa led by three chosen swains, The blushing captives of her virgin chains... When time's rude hand a bark of wrinkles spread Round her limbs, and silver'd o'er her head, Three other youths her riper years engage, The flatter'd victims of her wily age.

If this should sound like a perversion of Linnaeus's method, we may recall that the great Swedish botanist had written that "The flower's leaves ... serve as bridal beds which the creator has so gloriously arranged ... and perfumed with so many soft scents that the bridegroom with his bride might there celebrate their nuptials with so much greater solemnity. When now the bed is so prepared, it is time for the bridegroom to embrace his beloved bride and offer her his gifts."

Unsurprisingly, religious and conservative organizations began to express alarm. Most notably, the Encyclopaedia Britannica, published from the Calvinist redoubts of Edinburgh in 1768 , railed against the "disgusting strokes of obscenity" with which Linnaeus had disfigured the picture of nature's innocent beauties.

The illustrated book that best captured the tone of Darwinian rapture was Robert Thornton's majestic but failed enterprise, the New Illustration of the Sexual System of Linnaeus, first advertised to subscribers in 1797 and appearing in parts from 1799. The illustrations ranged from tabular and diagrammatic representations of Linnaeus's system, to romantic pictures of particular plants in evocative landscapes and highly charged allegories of nature. For example, Strelitzia reginae or 'queen plant', named after Charlotte of Mecklenburg-Strelitz, George III's queen, is soberly anatomized in one plate, depicted in an

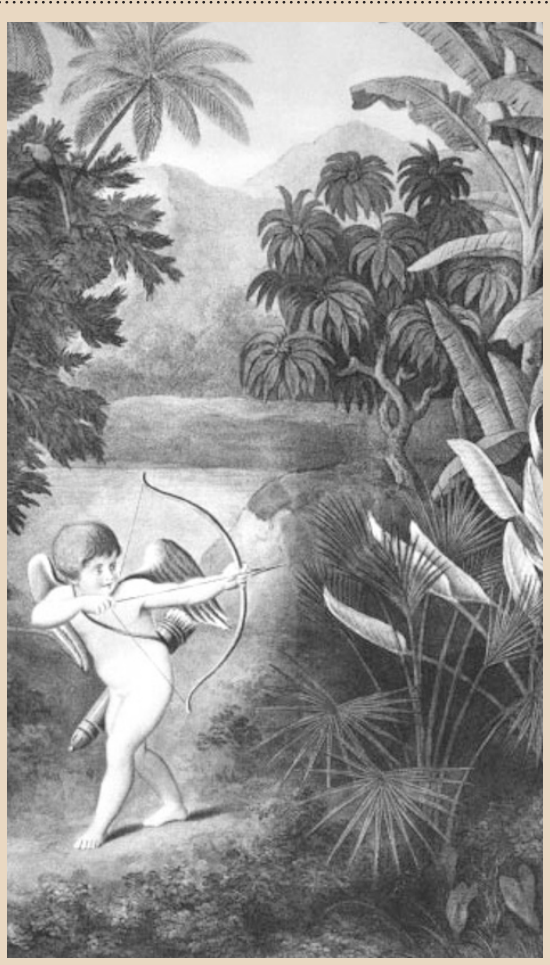

Philip Reinagle, "Cupid Inspiring the Plants with Love", from Robert Thornton's Temple of Flora, 1804, plate III.

exotic setting in another, and features as the target of Cupid's arrow in the allegorical image of "Cupid inspiring the plants with love" from the pictorial part of the New Illustration - re-titled in 1804 as The Temple of Flora.

However, lest we should think that Queen Charlotte was being encouraged to distribute her favours with Darwinian profligacy, Thornton is at pains to eulogize the royal patron of his enterprise as a "bright example of conjugal fidelity and maternal tenderness". Unshakeably pious, staunchly monarchist and very English, Thornton would have nothing to do with Erasmus Darwin's dangerously French attitudes.

Thornton argued that the mathematical, logical character of taxonomy was a "noble exercise" which was eminently suitable for the training of the minds of the young, who are all too easily seduced by pastimes that "inflame the passions". By stressing the dispassionate character of classification, he was consciously confronting the accusation that the sexual basis of Linnaeus's method was an obscene perversion of the innocence of plants and besmirched botany as a study unfit for young ladies. Thornton was determined that the Linnaean binomial system should serve as the taxonomic science of the flower bed and not as a justification for abandoning the proper regulation of the human nuptial chamber. Martin Kemp is in the Department of the History of Art, University of Oxford, 35 Beaumont Street, Oxford OX1 2PG, UK. 